Please do not remove this page

RMIT

UNIVERSITY

\title{
A comparison of underwater visual distance estimates made by scuba divers and a stereo-video system: Implications for underwater visual census of reef fish abundance
}

Harvey, Euan; Fletcher, David; Shortis, Mark; Kendrick, Gary

https://researchrepository.rmit.edu.au/esploro/outputs/9921858045701341/filesAndLinks?institution=61RMIT_INST\&index=null

Harvey, E., Fletcher, D., Shortis, M., \& Kendrick, G. (2004). A comparison of underwater visual distance estimates made by scuba divers and a stereo-video system: Implications for underwater visual census of reef fish abundance. Marine and Freshwater Research, 55, 573-580. https://doi.org/10.1071/mf03130 Document Version: Accepted Manuscript

Published Version: https://doi.org/10.1071/mf03130

Repository homepage: https://researchrepository.rmit.edu.au

(c) CSIRO 2004

Downloaded On 2023/04/27 00:11:51 +1000 
A comparison of underwater visual distance estimates made by SCUBA divers and a stereovideo system: Implications for underwater visual census of reef fish abundance.

Euan Harvey $^{1}$, David Fletcher ${ }^{2}$, Mark Shortis ${ }^{3}$ and Gary Kendrick ${ }^{1}$

${ }^{1}$ School of Plant Biology, Faculty of Natural and Agricultural Sciences, University of Western Australia, 35 Stirling Highway, Crawley, Western Australia 6009.

${ }^{2}$ Department of Maths and Statistics, University of Otago, 539 Castle Street, Dunedin, New Zealand.

${ }^{3}$ Faculty of Engineering, RMIT University, GPO Box 2476V Melbourne 3001, Victoria, Australia.

Corresponding author: Euan Harvey School of Plant Biology, Faculty of Natural and Agricultural Sciences, University of Western Australia, 35 Stirling Highway, Crawley, Western Australia 6009.

E-mail euanh@cyllene.uwa.edu.au

$\mathrm{Ph}+61(08) 93802416$

Fax +61 (08) 93801001

Citation:

Harvey, E, Fletcher, D, Shortis, M and Kendrick, G 2004, 'A comparison of underwater visual distance estimates made by scuba divers and a stereo-video system: Implications for underwater visual census of reef fish abundance', Marine and Freshwater Research, vol. 55, pp. 573-580. 


\begin{abstract}
Underwater visual census of reef fish by SCUBA divers is a widely used and useful technique for quickly evaluating the composition and abundance of reef fish assemblages, but suffers from biases and errors in estimates of distance to, and the length of fish. Here we present the errors associated with underwater visual estimates of distance made by novice and experienced scientific divers and compare them to an underwater stereo video system. We then demonstrate the potential implications of these biases and errors on underwater visual census assessments of reef fish abundance and how the accuracy and precision of SCUBA diver length estimates of fish is affected as distance increases. Distance was under-estimated by both experienced (mean relative error $=-11.7 \%$, standard deviation $=21.4 \%$ ) and novice scientific divers (mean relative error $=-5.0 \%$, standard deviation $=17.9 \%$ ). For experienced scientific divers this error may potentially result in an $82 \%$ under-estimate, or $194 \%$ over-estimate of the actual area censused and will affect estimates of fish density. The stereo-video system also under-estimated distance, but to a much lesser degree (mean relative error $=-0.9 \%$, standard deviation $=$ 2.6\%) and with less variability than divers resulting in consistent areas being censused. To minimise the effects of distance error SCUBA divers using underwater visual census for estimating densities and lengths of fish should routinely calibrate their distance estimates in the same way that fish length calibrations are made presently. There was no relationship between the relative error of length estimates and the distance of the fish away from the observer.
\end{abstract}




\section{Introduction}

Visual survey techniques are widely used for determining the abundance of both terrestrial (Caughley et al. 1976; Caughley 1977; Cormack et al. 1979; Ralph and Scott 1981; Francis 1994) and marine organisms (Estes and Gilbert 1978; Marsh and Sinclair 1989). These techniques were first used for assessing the abundance of reef fishes in the 1950s (Brock 1954; Odum and Odum 1955). Since then they have been further developed and widely applied. Underwater Visual Census (UVC) techniques have become popular, as they are relatively quick, non-destructive, repeatable and cost effective (St. John et al. 1990; English et al. 1994; Watson et al. 1995; Thompson and Mapstone 1997). There are also a number of disadvantages and biases (see Harvey et al., 2002a). Three different types of UVC techniques are commonly used; transects, point counts and Rapid Visual Censuses (RVC), or timed counts. Strip transects are the most prevalent (Kingsford and Battershill 1998). When assessing the abundance of reef fish using a strip transect, a SCUBA diver normally swims along a marked transect rope or tape measure of a predetermined length and counts all the fish encountered within a set distance either side of the centre of the transect over a predetermined distance. Point counts are slightly different in that the SCUBA diver counts all the fish within a circle of a predetermined radius. During RVC counts, the SCUBA diver records all fish seen within a lane of estimated width over a predetermined time, effectively making many RVC techniques a strip transect of variable length. A feature common to all of these techniques is that the SCUBA diver has to decide whether a fish is inside or outside the boundary of the sampling unit. In all cases the SCUBA diver will subconsciously or consciously estimate the cross substratum distance to the fish, and decide whether or not 
to include the fish in the count. While some researchers physically mark the boundary of their transects or point counts (Bell 1983; Choat and Bellwood 1985; Thresher and Gunn 1986; McCormick and Choat 1987; Lincoln-Smith 1988; Bortone et al. 1989; Davis and Anderson 1989; Polunin and Roberts 1993; Russ and Acala 1996; Rakitin and Kramer 1997) many do not, making the task for the SCUBA diver even more demanding. The decision to include or exclude a particular fish is further complicated if the fish moves rapidly across the sample unit boundary (Watson et al. 1995). The SCUBA diver then has to decide whether the fish was inside or outside the sample unit when it was first sighted (Andrew and Mapstone 1987). It is clear that systematic errors in distance estimation leads to bias in the count of the number of fish within the sample unit, and hence in overall estimate of fish abundances (Bohnsack and Bannerot 1986; Thresher and Gunn 1986).

The accuracy and precision of in situ UVC length estimates of reef fish has been the focus of some detailed researched (Bell et al. 1985; St. John et al. 1990; Darwall and Dulvy 1996; Harvey et al. 2001 a; b; 2002), however the effect of increasing distance on the accuracy and precision of in situ UVC length estimates has not been investigated.

The objectives of this study were to:

1. compare the accuracy and precision of visual estimates of distance made by novice and experienced scientific SCUBA divers and a stereo-video system;

2. demonstrate how errors associated with estimating distance affect abundance estimates of reef fish. 
3. demonstrate the effect of increasing distance on the accuracy and precision of length estimates of fish made by novice and experienced scientific SCUBA divers under both controlled and field conditions.

\section{Methods}

\section{Visual estimates of distance}

The accuracy and precision of visual distance estimates made by experienced and novice scientific divers were tested by a simple procedure routinely used for calibrating diver estimates of the lengths of reef fish (GBRMPA 1979; Bell et al. 1985; English et al. 1994). Typically, PVC sticks or silhouettes of fish are placed in the water and their lengths estimated. The accuracy of the diver estimate is then assessed from the difference between the real size and the estimate. In this study, experienced and novice scientific divers were asked to swim along either a fibreglass surveyors tape or a lead transect rope marked at 1 metre intervals and estimate the distance to each silhouette from marked positions. Sixteen plastic silhouettes of fish, ranging in length from 10 to $49 \mathrm{~cm}$, were placed at distances of between 3.0 and 6.6 metres from the marked positions. Trials took place in either a saltwater aquarium or a freshwater pool. 6.6 metres was selected as the maximum distance from which estimates could be made as visibility was never greater than 7 metres in the saltwater aquaria. Each of the experienced and novice scientific divers swam five repeat transects. The distances from the transect rope and the order of the silhouettes was maintained throughout the experiment. Data were recorded on an underwater slate which was replaced between transects so the divers could not refer back to a previous measurement. Distance data were not made available to either the novice or experienced scientific divers between dives to avoid memorisation of previous 
distance estimates for a particular silhouette. The mean error, standard deviation and the standard error for each of the sixteen fish was calculated for each of the novice and experienced scientific divers.

In many respects the trial represents a best case scenario. The silhouettes were stationary and the SCUBA divers were given no time limits to estimate the cross substratum distance from the point of observation to the silhouette. Consequently, they had time to use the distance measures on the surveyor's tape or the marked intervals on the lead transect rope to help scale their estimates. Additionally, there were many other objects in the saltwater aquarium (eg. building bricks, tiles, fish and support pillars) and in the swimming pool (swimmers and lane markings) that could be used to scale the estimates.

\section{Novice scientific divers}

Novice scientific divers were defined as experienced SCUBA divers who had made few, if any estimates of the lengths of reef fish underwater but were all experienced at undertaking scientific observations in other disciplines. Eight novice scientific divers made visual underwater distance estimates in a saltwater pool at the Portobello Marine Laboratory (PML) between May 1994 and January 1995. No more than two transects were completed on any one-day except for one diver who completed four consecutive transects in one day.

\section{Experienced scientific divers}

Experienced scientific divers were considered active marine scientists who had been, or who were currently involved in research that required them to make counts of reef fish abundance. Five experienced scientific divers made underwater visual estimates of the 
distances to the plastic silhouettes between October 1994 and June 1996. Three of the divers made their estimates in a saltwater pool at PML whilst the other two made their estimates in freshwater swimming pools elsewhere. Due to time constraints of diver availability, all of the distance estimates were made on consecutive transects during one dive.

Water clarity between the saltwater and freshwater pools was different. As each diver completed all of their estimates under the same conditions we do not consider this to be a major flaw. Under field conditions water clarity is a factor that may change substantially throughout a dive.

\section{Stereo-video estimates of distance}

Stereo-video camera estimates of distance were obtained on 20 November 1997 in a freshwater swimming pool. Three silhouettes of different lengths were held in front of the stereo-video camera and their images recorded at 1 metre intervals between 3 and 12 metres. Three replicate images were recorded for each silhouette at each distance. The mean of ten repeat measurements was calculated for each of the three replicate images recorded for each of the three silhouettes at each distance. The actual distance, from the

silhouette to the centre of the camera, was measured using a fibreglass surveyors tape. A detailed description of the stereo-video system, calibration and measurement procedures may be found in Harvey and Shortis $(1996,1998)$ and Shortis and Harvey 1998).

\section{Assessing the effect of distance error on estimates of abundance}

To graphically demonstrate the potential impact of distance errors and bias on UVC estimates of reef fish abundance, a hypothetical model was created. The results presented 
here are based on point counts only, as the results for strip transects are very similar (Harvey 1998) and any general conclusions are equally applicable.

Radial distances for published point counts range from 3m (Francour, 1997) and 5.64m (Bortone et al. 1989) to 15m (Thresher and Gunn 1986). Francour (1997) notes that the radial distance scanned should correspond to $2 / 3$ of the maximum visibility. Most commonly, radial distances of 7.5m (Bohnsack et al. 1994) and 7m (Samoilys 1992; Samoilys and Carlos 1992; Jennings and Polunin 1995) have been used. To keep with common practice, we used a radial distance of 7 metres for the theoretical point count in our two-dimensional model. This point count, covering an area of $154.1 \mathrm{~m}^{2}$ was positioned in the centre of a theoretical $20 \mathrm{~m} \times 20 \mathrm{~m}$ square $\left(400 \mathrm{~m}^{2}\right)$. Circles representing the upper and lower 95\% confidence limits for the range of the actual area censused by novice and scientific divers and the stereo-video system were also created (see Figures 2a, 2b and 2c). We calculated a 95\% confidence interval for the actual distance associated with an estimated distance, using inverse regression (Draper and Smith 1981). The confidence interval for the actual distance was then converted into a confidence interval for the actual area censused, from which we calculated the potential error associated with the estimated fish density. Potential error in estimated fish density was determined by randomly allocating fifty points, symbolising fish, a location within the 20 x 20 m square. Counts were then made of the number of fish symbols falling within the actual area of the point count and the upper and lower 95\% confidence intervals for the novice and scientific divers and the stereo-video system. This was 
repeated fifty times based on the confidence intervals for the novice and experienced scientific divers and the stereo-video system.

\section{Assessing the effect of increasing distance on the accuracy and precision of UVC length estimates}

Data on the accuracy and precision of in situ UVC length estimates by novice and experienced scientific divers was collected in the same experiment and manner as described above with divers estimating the length of each silhouette as it was encountered. An analysis of this data has been presented in Harvey et al. (2001a) but the relationship between errors in length estimates as distance increases was not investigated. Similarly, the accuracy and precision of in situ length estimates made in the field by three experienced observers was presented in Harvey et al. (2002a) but the relationship between the accuracy and precision of length estimates was not investigated. Details of the experimental design maybe found in Harvey et al. (2002a). We examine the relationships between errors in length estimates and increasing distance using both these data sets.

\section{Analysis of data}

Novice and experienced scientific divers

The results for the novice and experienced scientific divers were summarised prior to further analysis by calculating, for each silhouette and each observer, the mean distance estimate over all transects. The repeat transects were therefore used solely to provide a reliable estimate of the error made by each diver on the distance away of each silhouette. 
The individual divers provide replication. For each diver, the relative error (RE) at each distance was calculated as a percentage using:

Relative error $=(($ Mean estimated distance - Actual distance $) /$ Actual distance $) * 100$ where the mean estimated distance was over all transects. The overall RE at each distance was the mean relative error across all observers. The variation at each distance was summarised by the coefficient of variation (CV) among observers of the mean estimated distance. CV was calculated as:

Coefficient of Variation $=($ SD of mean estimated distance/Actual distance $) * 100$ It might be expected that both the error in estimating distance and the variation between observers would be proportional to the distance. This would imply that RE and CV would both be consistent across a range of distances, allowing us to assume a single overall RE and $\mathrm{CV}$. We checked this by regressing both RE and CV against distance.

\section{Stereo-video distance}

For each replicate image, the RE for each combination of distance and silhouette was calculated as for observers, with the mean estimated distance over the ten repeat measurements. The overall RE for each combination of distance and silhouette was the mean across the three images. The variation at each combination of distance and silhouette was summarised by the CV among images of the mean estimated distance. As for the divers, we regressed both RE and CV against distance to check their consistency across a range of distances.

\section{Length data}


Errors in length estimates from novice and experienced scientific divers (Harvey et al. 2001a) and from the three experienced field observers (Harvey et al. 2002a) were converted to relative error, graphically summarised and relationships between error in increasing distance explored by regressing RE against distance analysis. We used regression analysis as it might be expected that error in length estimates would be proportional to the distance. Length errors were converted to RE because fishes of different lengths were estimated over a range of distances. Length errors associated field estimates were made by comparing the SCUBA diver estimate to simultaneous measurements with a stereo-video system. The upper or lower 95\% confidence limits for the stereo-video was used as the real value (see Harvey et al. 2002a) to compare to the SCUBA diver estimates, and therefore these data represent a best case scenario. The accuracy and precision of stereo-video estimates of fish length as distance increase are reported in Harvey et al. (2002b).

\section{Results}

\section{Visual estimates of distance}

Novice scientific divers

Novice scientific divers tended to underestimate distances (mean error $=-6.25 \mathrm{~cm}, \mathrm{SE}=$ $25.62 \mathrm{~cm}$, see Figure 1) and had a mean RE of $-5 \%$ (Table 1). Also, RE increased with distance $(\mathrm{t}=2.97, \mathrm{df}=14, \mathrm{P}=0.010)$, and ranged from $-20 \%$ to $+16 \%$. Similarly, $\mathrm{CV}$ for novice scientific divers increased with distance $(\mathrm{t}=2.37, \mathrm{df}=14, \mathrm{P}=0.030)$. CV values ranged from $13 \%$ to $26 \%$ with a mean of $17.9 \%$ (Table 1 ). 
Experienced scientific divers

Experienced scientific divers also tended to underestimate distances (mean error = $46.22 \mathrm{~cm}, \mathrm{SE}=32.44 \mathrm{~cm}$, see Figure 1) and had a mean RE of $-11.7 \%$ (Table 1). For experienced scientific divers there was no evidence that RE changed with distance $(\mathrm{t}=$ $0.52, \mathrm{df}=14, \mathrm{P}=0.614)$. The $\mathrm{RE}$ values ranged from $-17 \%$ to $-8 \%$. CV for experienced scientific divers significantly decreased with distance $(\mathrm{t}=-3.14, \mathrm{df}=14, \mathrm{P}=0.007) . \mathrm{CV}$ ranged from $9 \%$ to $34 \%$ with a mean of $21.4 \%$ (Table 1 ).

\section{Stereo-Video}

Estimates made from stereo-video also tended to underestimate distance, but to a much lesser degree. A mean error of $-10.24 \mathrm{~cm}(\mathrm{SE}=5.14 \mathrm{~cm})$ was recorded across all distances and decreased to $-0.25 \mathrm{~cm}(\mathrm{SE}=3.51 \mathrm{~cm})$ between distances of 3 and $7 \mathrm{~m}$, comparable to the distances over which divers were tested. For stereo-video, RE decreased with distance $(\mathrm{t}=-8.19, \mathrm{df}=28, \mathrm{P}<0.0001)$. The RE values ranged from $3.8 \%$ to $+2.4 \%$. There was no evidence that CVs for stereo-video changed with distance $(\mathrm{t}=-0.58, \mathrm{df}=28, \mathrm{P}=0.57)$. The $\mathrm{CV}$ values ranged from $0.02 \%$ to $6.9 \%$.

During underwater recordings it was noted that over larger distances sag in the surveyors tape could not be completely eliminated, even though the tape was pulled taut. The effect of the tape sagging can be seen in the differences in the mean errors for all distances and for those up to $7 \mathrm{~m}$, with an increasing mean negative error and increasing variation at 7 metres and beyond (Figure 1). 


\section{Effect of distance error on sampling area and counts of abundance: Point Counts}

\section{Novice scientific divers}

The actual boundary of a $7 \mathrm{~m}$ point count, as perceived by novice scientific divers, could in reality lie between $5.3 \mathrm{~m}$ and $8.1 \mathrm{~m}$. An accurate $7 \mathrm{~m}$ point count will census an area of $154.1 \mathrm{~m}^{2}$. According to these results the actual area censused by novice observers may range between $89.0 \mathrm{~m}^{2}$ and $207.40 \mathrm{~m}^{2}$ (Figure 2a) or between $58 \%$ and 134\% (Table 2) of the actual area. In terms of abundance, as few as 8 fish may be counted if the novice observer over estimates or as high as 38 fish if he or she under estimates the count of all the fish within the upper 95\% CI border (Table 3).

\section{Experienced scientific divers}

A fish estimated by an experienced scientific diver as being at the edge of a $7 \mathrm{~m}$ point count could actually be at a distance of between $6.3 \mathrm{~m}$ and $9.7 \mathrm{~m}$. The actual area censused ranged between $127.7 \mathrm{~m}^{2}$ and $286.8 \mathrm{~m}^{2}$ (Figure $2 \mathrm{~b}$ ) or between $82 \%$ and $194 \%$ of the real area (Table 2). For the estimated $154.1 \mathrm{~m}^{2}$ supposedly censused by the point count, abundance could range from as low as 5 fish (lower 95\% CI) to as high as 38 fish (upper 95\% CI) (Table3).

\section{Stereo-video}

Using a stereo-video, a fish estimated as being at the edge of the $7 \mathrm{~m}$ point count could actually be at a distance of between $6.7 \mathrm{~m}$ and $7.4 \mathrm{~m}$, with the actual area censused being between $143.7 \mathrm{~m}^{2}$ and $173.9 \mathrm{~m}^{2}$ (Figure 2c). The actual area censused will fall between 93\% and $113 \%$ of the actual area (Table 2). In terms of fish counted, abundance estimates may range between 20 fish (lower CI) to 24 fish (upper CI) (Table 3). 


\section{The relationship between in situ length estimates and increasing distance}

Figures 3a and 3b show that for length estimates made in a controlled environment by novice and experienced scientific divers there does not appear to be a relationship between relative error and distance. Regressing relative error against distance shows weak relationships between relative error and distance (Novice scientific divers $\mathrm{R}^{2}$ $=7.1 \%$ RE Novice $=-0.237993+0.0779883$ Distance; Experienced scientific divers $\mathrm{R}^{2}$ $=10.4 \%$, RE Experienced $=-0.344252+0.0617702$ Distance $)$.

Figures 4a, b and c show that for experienced scientific divers operating under field conditions there does not appear to be any relationship between the magnitude of the relative error of length estimates and increasing distance. This supported by the regression analysis which shows weak relationships between relative error and increasing distance $\left(\right.$ Diver $1 \mathrm{R}^{2}=0.9 \%$, Diver $1 \mathrm{RE}=0.194798-0.0331412$ Distance; Diver $2 \mathrm{R}^{2}=$ 1.8\%, Diver $2 \mathrm{RE}=0.507170$ - 0.0890697 Distance; Diver $3 \mathrm{R}^{2}=7.9 \%$, Diver $3 \mathrm{RE}=$ 0.437826 - 0.0924894 Distance).

\section{Discussion}

Both inexperienced and experienced scientific divers are shown to be unable to accurately estimate the distance to fishes. This impacts on the total area surveyed in UVC methods. This is a problem that has been recognised previously. Choat and Bellwood (1985) noted that the 5m distance which represented half the transect width of their 30m x 10m transects was initially under-estimated, and that there was a tendency to include larger fish in the transect when they were in fact outside. Four of the five experienced scientific divers used in this research tended to under-estimate distances 
(mean $\mathrm{RE}=-20 \%$; range $=-29 \%$ to $0 \%$ ), while one tended to over-estimate (mean RE = $+20 \%$; range $=-7 \%$ to $+46 \%$ ). For the novice scientific divers there was a tendency to both over-estimate and under-estimate (mean $\mathrm{RE}=-5 \%$; range $=-44 \%$ to $+58 \%$ ). Thompson and Mapstone (1997) report that a large proportion of the variation in surveys is attributable to differences between observers. Thresher and Gunn (1986) note that error in distance estimates has considerable influence on the area of the censused sample unit, and consequently the number of fish recorded per sample. Under-estimates in distance (like those predominantly recorded by our experienced scientific divers) result in a larger area being surveyed, and more fish being counted. Based on the errors recorded by the experienced scientific divers the $95 \%$ CI borders indicate that the area censused by and experienced scientific diver could lie between $82 \%$ and $194 \%$ of the actual survey area.

If bias is consistent within and among individual divers then it is possible to not only compare data sets, but also to develop a calibration equation that allows biased measurements to be corrected (Buckland et al. 1993). Therefore, we recommend that distance calibration become a standard practice in UVC in the same way that length calibrations are undertaken (eg. Bell et al. 1985).

Distance estimates made from either the stereo-video system or by the experienced and novice scientific divers were made in controlled environments (saltwater aquaria, swimming pools). It is very likely that the accuracy and precision of distance estimates to a fish made by a diver will decrease when they have to contend with varying 
conditions of lighting and water visibility in the presence of surges and currents (Harvey et al. 2002a). Past experience has shown that the accuracy and precision of the stereovideo measurements will not change (Harvey and Shortis 1996; Harvey and Shortis 1998; Harvey et al. 2001a) provided calibrations are made within that system and a series of guidelines are followed about how measurements should be made (Harvey et al. 2002b).

Such error and inter-observer variability in estimates of distance as described in this paper have serious implications for comparisons of data sets between different observers and among different surveys sampled at different times. Stereo-video does not completely eliminate error in distance estimates but it does substantially improve the accuracy and precision of estimates. The additional costs of using stereo-video technology include the purchase of two video cameras and underwater housings, a base bar to mount the video cameras on, a synchronisation diode, a PC frame grabber and the software for analysing the resulting imagery. There is also processing time required back in the laboratory. It has been shown that volunteers can operate both the measurement software in the laboratory and the stereo-video system in the field without compromising data quality (Harvey et al. 2001a). However, the use of stereo-video raises issues of the detectability of fishes by the cameras. A diver moving along a transect, or within a point count has the advantage of having a greater field of view and can move about the axis of the transect or midpoint of the point count looking into crevices and behind rocks. A stereovideo system is forward pointing and will not detect fish that are behind rocks or in crevices unless the operator swims the system into those areas. Additionally, a diver can 
sample at multiple scales where as the stereo-video system is deliberately preconfigured to sample a specific area.

When sampling multi-species fish assemblages larger and more mobile reef fishes are sampled first using a larger sampling unit (example a 50 × $10 \mathrm{~m}$ transect) and smaller cryptic species sampled using a more intensive search of a smaller unit (example 50 x 2 m transects) (Kingsford and Battershill 1998; English et al. 1994). It is widely accepted that divers conducting UVC will become overloaded and inefficient when they try to sample too many species at one time (Greene and Alevizon 1989; Kingsford and Battershill 1998; English et al. 1994). Perhaps the best combination is for a diver to swim a stereo-video setup while wearing a fullface mask with a microphone to record audio observations onto one of the videotapes in one of the two video cameras (eg. Westera et al. 2003).

Surprisingly the data on the relationship between the relative error of UVC length estimates and distance shows no relationship as distance increases. Error is length estimates appears to be fixed as distance increases. However, the data do highlight the variability in the precision of the length estimates. This variability will affect the statistical power of programs using UVC methods to detect changes in the mean length of fish (Harvey et al. 2001b). 


\section{Conclusion}

This research demonstrates that error in visual distance estimates made by novice and highly experienced scientific divers can be large, and that this error has the potential to affect the size of the sample units censused. This in turn will affect numbers of fish counted by a census and the comparison of data collected by different observers and across different censuses by the same observer. It is essential that observer biases inherent in visual surveys are minimised or standardised through calibrations in order to detect changes in fish assemblages using UVC techniques. This is very important for multi-species surveys carried out over large temporal (regional or continental) and/or spatial scales. Particularly to those research programs investigating the effects of Marine Protected Areas if multi-species data sets collected by different observers at different times are to have any statistical power to support the conclusions they draw.

Stereo-video had less error associated with distance estimates than either novice or scientific divers and may offer a cost-effective tool for removing many observer biases.

\section{Acknowledgements}

The authors acknowledge grants and financial aid from the New Zealand Department of Conservation (Research Grant \#1822), the University of Otago Research Committee, the Southland Regional Council (New Zealand) and the Division of Sciences at the University of Otago, Dunedin, New Zealand that made this research possible. Also acknowledged is support from Sony New Zealand Ltd, THC Milford Sound, Fiordland Lobster Company and Mobil and Gore Services Ltd. This work was completed thanks to postdoctoral fellowship funding from the New Zealand Foundation for Research Science 
and Technology and the University of Western Australia to Euan Harvey. The authors are grateful to Chris Battershill June Hill, Justin McDonald, Philip Mladenov and Di Watson and for comments and suggestions on this manuscript. Additionally, our thanks to all novice and experienced scientific observers who willingly gave their time to assist with this research and to two anonymous referees for their constructive comments.

\section{Bibliography}

Andrew, N. L., and B. D. Mapstone. (1987). Sampling and the description of spatial pattern in marine ecology. Oceanography and Marine Biology Annual Review 25: 3990.

Bell, J. D. (1983). Effects of depth and marine reserve fishing restrictions on the structure of a rocky reef fish assemblage in the north-western Mediterranean Sea. Journal of Applied Ecology 20: 357-369.

Bell, J. D., G. J. S. Craik, D. A. Pollard, and B. C. Russell. (1985). Estimating length frequency distributions of large reef fish underwater. Coral Reefs 4: 41-44.

Bohnsack, J. A., and S. P. Bannerot. (1986). A stationary visual census technique for quantitatively assessing community structure of coral reef fishes. NOAA.

Bohnsack, J. A., D. E. Harper, D. B. McClellan, and M. Hulsbeck. (1994). Effects of reef size on colonisation and assemblage structure of fishes at artificial reefs off southeastern Florida, U.S.A. Bulletin of Marine Science 55: 796-823.

Bortone, S. A., J. J. Kimmel, and C. M. Bundrick. (1989). A comparison of three methods for visually assessing reef fish communities: Time and area compensated. Northeast Gulf Science 10: 85-96. 
Brock, V. E. (1954). A preliminary report on a method of estimating reef fish populations. Journal of Wildlife Management, 18: 297-308.

Buckland, S. T., D. R. Anderson, K. P. Burnham, and J. L. Laake. (1993). Distance sampling. Estimating abundance of biological populations. Chapman \& Hall, London. Caughley, G. (1977). Analysis of vertebrate populations. Wiley, London.

Caughley, G. R., R. Sinclair, and D. Scott-Kemmis. (1976). Experiments in aerial survey. Journal of Wildlife Management 40: 290-300.

Choat, J. H., and D. R. Bellwood. (1985). Interactions amongst herbivorous fishes on a coral reef: influence of spatial variation. Marine Biology 89: 221-234.

Cormack, R. M., G. P. Patil, and D. S. Robson, eds. (1979). Sampling biological populations. International Co-operative Publishing House, Fairland.

Davis, G. E., and T. W. Anderson. (1989). Population estimates of four kelp forest fishes and an evaluation of three in situ assessment techniques. Bulletin of Marine Science 44: $1138-1151$.

Draper, N. R., and Smith, H. (1981). Applied Regression Analysis. Wiley, New York. 709 p.

English, S., C. Wilkinson, and V. Baker, eds. (1994). Survey Manual for Tropical Marine Resources, 368 p. [Available from the Australian Institute of Marine Science. P.M.B. No. 3. Townsville Mail Centre, Australia, 4810.]

Estes, J. A., and J. R. Gilbert. (1978). Evaluation of an aerial survey of Pacific Walruses (Odobenus rosmarus divergens). Journal of the Fisheries Research Board of Canada 35: $1130-1140$. 
Francis, C. M. (1994). Population changes of boreal forest ducks - A comment. Journal of Wildlife Management 58: 582-586.

Francour, P. (1997). Fish assemblages of Posidonia oceanica beds at Port-Cros (France, NW Mediterranean): Assessment of composition and long-term fluctuations by visual census. Marine Ecology 18: 157-173.

GBRMPA (Great Barrier Reef Marine Park and Authority). 1979. Workshop on coral trout assessment techniques: workshop series 3. G.B.R.M.P.A., Queensland, Australia, $64 \mathrm{p}$.

Greene, L. E., and W. E. Alevizon. (1989). Comparative accuracies of visual assessment methods for coral reef fishes. Bulletin of Marine Science 44: 899-912.

Harvey, E. S., and M. R. Shortis. (1996). A system for stereo-video measurement of subtidal organisms. Journal of the Marine Technology Society 29: 10-22.

Harvey, E. S. (1998). Underwater stereo-video: A tool for minimising the biases in visual censuses of reef fish. PhD Thesis, Department of Marine Science, University of Otago, New Zealand.

Harvey, E. and Shortis, M. R. 1998. Calibration stability of an underwater stereo-video system: Implications for measurement accuracy and precision. Marine Technology Society Journal, 32(2) : 3-17.

Harvey, E. S., Fletcher, D., and M. R. Shortis. (2001a). A comparison of the precision and accuracy of estimates of reef-fish lengths made by divers and a stereo-video system. Fishery Bulletin 99(1): 63-71.

Harvey, E. S., Fletcher, D., and Shortis, M. 2001b. Improving the statistical power of visual length estimates of reef fish: A comparison of estimates determined visually by 
divers with estimates produced by a stereo-video system. Fishery Bulletin, 99(1): 7280.

Harvey, E. S, Fletcher, D., and M. R. Shortis. (2002a). Estimation of reef fish length by divers and by stereo-video. A first comparison of the accuracy and precision in the field on living fish under operational conditions. Fisheries Research 57(3): 257-267.

Harvey, E. S., Shortis, M. R., Stadler, M. and M. Cappo. (2002b). A comparison of the accuracy and precision of digital and analogue stereo-video systems. Marine Technology Society Journal 36(2): 38-49.

Jennings, S., and N. V. C. Polunin. (1995). Biased underwater visual census biomass estimates for target-species in tropical reef fisheries. Journal of Fish Biology 47: 733736.

Kingsford, M. and C. Battershill. (1998). Studying temperate marine environments. A handbook for ecologists. Canterbury University Press, 335 p.

Lincoln Smith, M. P. (1988). Effects of observer swimming speed on sample counts of temperate rocky reef fish assemblages. Marine Ecology Progress Series 43: 223-231.

Marsh, H., and D. F. Sinclair. (1989). Correcting for visibility bias in strip transect aerial surveys of aquatic fauna. Journal of Wildlife Management 53: 1017-1024.

McCormick, M. I., and J. H. Choat. (1987). Estimating total abundance of a large temperate reef fish using visual strip-transects. Marine Biology 96: 469-478.

Odum, H. T., and E. P. Odum. (1955). Trophic structure and productivity of a windward coral reef community on Eniwetok Atoll, Marshall Islands. Ecological Monograph 25: 291-320. 
Polunin, N. V. C., and C. M. Roberts. (1993). Greater biomass and value of target coral reef fishes in two small Caribbean marine reserves. Marine Ecology Progress Series 100: $167-176$.

Rakitin, A., and D. L. Kramer. (1996). Effect of a marine reserve on the distribution of coral reef fishes in Barbados. Marine Ecology Progress Series 131: 97-113.

Ralph, C. J., and J. M. Scott, eds. (1981). Estimating numbers of terrestrial birds. Allen Press, Lawrence.

Russ, G.R. and A.C. Alcala. 1996. Marine reserves: Rates and patterns of recovery and decline of large predatory fish. Ecological Applications 6: 947-961.

Samoilys, M. A. (1992). Review of the underwater visual census method developed by the DPI/ACIAR project: visual assessment of reef fish stocks. Conference Workshop Series. Queensland Department of Primary Industries.

Samoilys, M. A., and G. Carlos. (1992). Development of an underwater visual census method for assessing shallow water reef fish stocks in the south west Pacific. Queensland Department of Primary Industries, Northern Fisheries Centre, Cairns.

Shortis, M. R. and Harvey, E. S. 1998. Design and calibration of an underwater stereovideo system for the monitoring of marine fauna populations. International Archives Photogrammetry and Remote Sensing, 32(5) : 792-799.

St. John, J., Russ, G. R., and W. Gladstone. (1990). Accuracy and bias of visual estimates of numbers, size structure and biomass of coral reef fish. Marine Ecology Progress Series 64: 253-262.

Thompson, A. A., and B. D. Mapstone. (1997). Observer effects and training in underwater visual surveys of reef fishes. Marine Ecology Progress Series 154: 53-63. 
Thresher, R. E., and J. S. Gunn. (1986). Comparative analysis of visual census techniques for highly mobile, reef associated piscivores (Carangidae). Environmental Biology of Fishes 17: 93-116.

Watson, R. A., G. M. Carlos, and M. A. Samoilys. (1995). Bias introduced by the nonrandom movement of fish in visual transect surveys. Ecological Modelling 77: 205214.

Westera, M., Lavery, P. and G. Hyndes. (2003). Differences in recreationally targeted fishes between protected and fished areas of a coral reef marine park. Journal of Experimental Marine Biology and Ecology 294: 145 - 168. 
Novice Scientific Divers

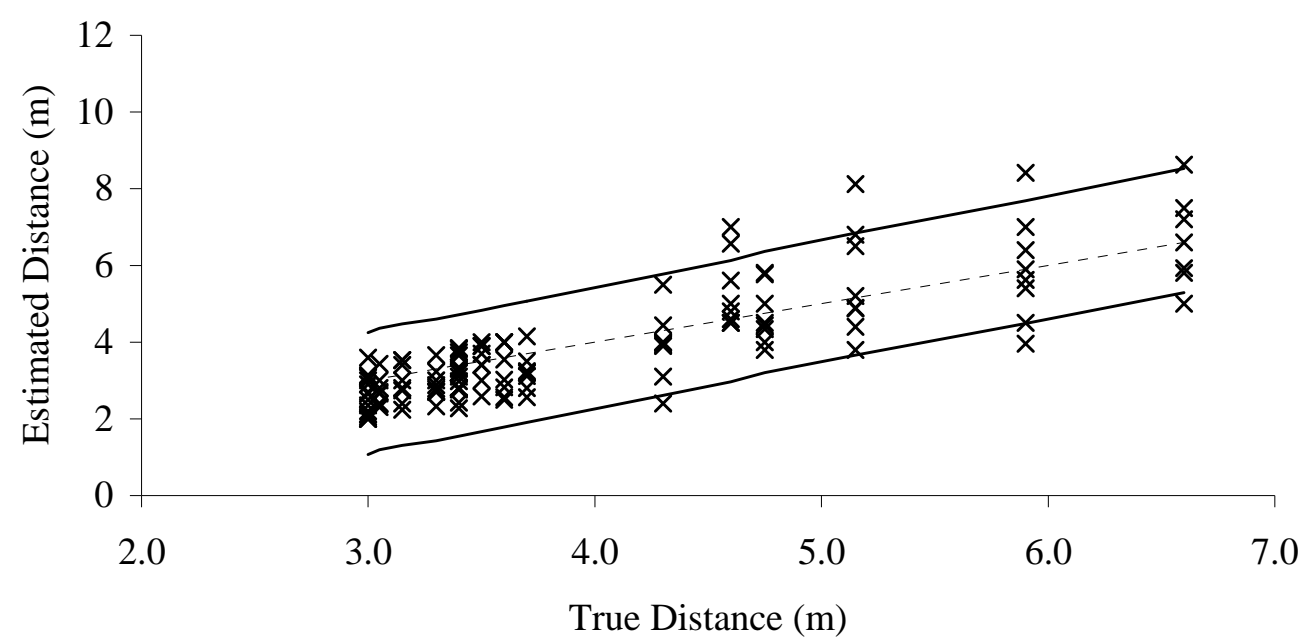

Experienced Scientific Divers

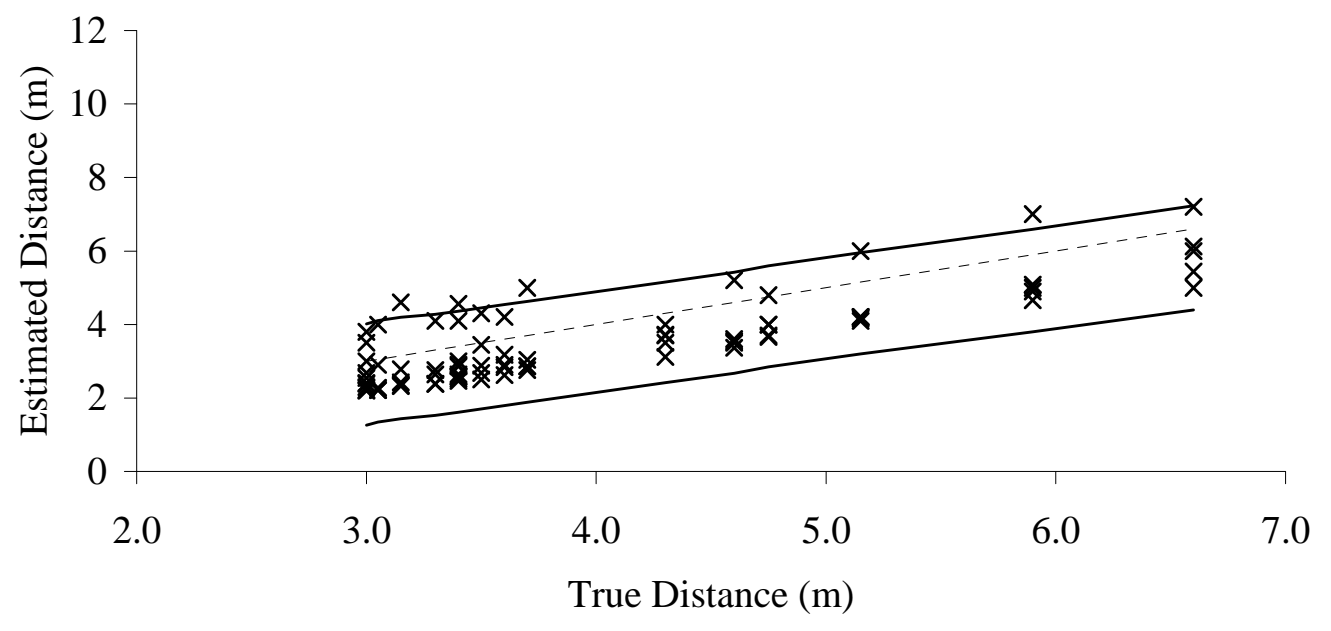


Stereo-Video

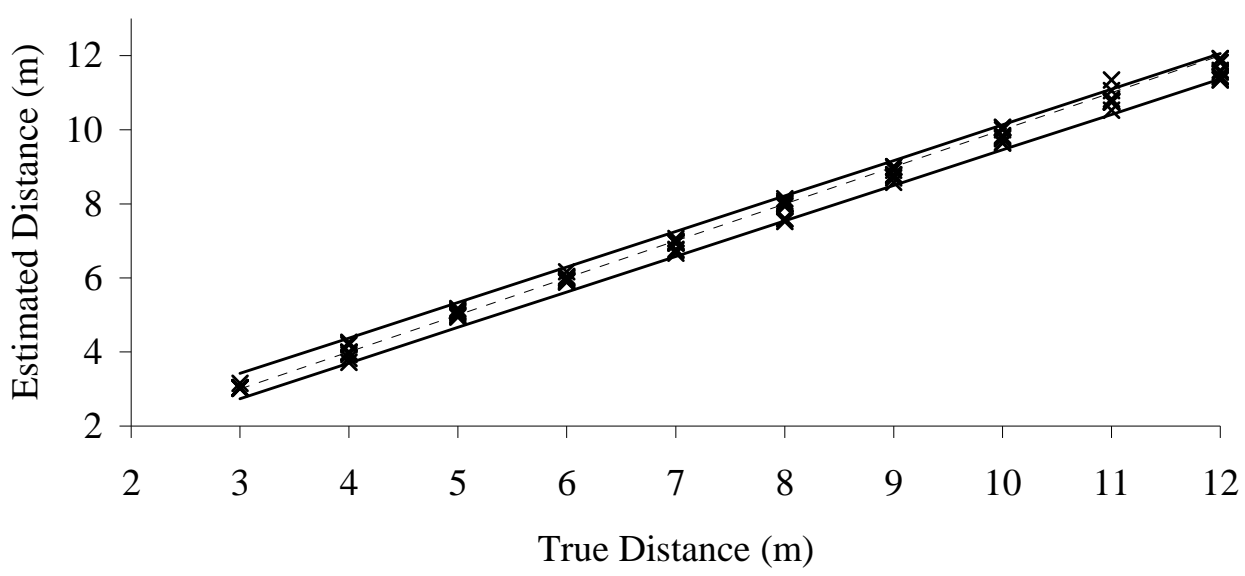

Figure 1 
Figure 2 (a)

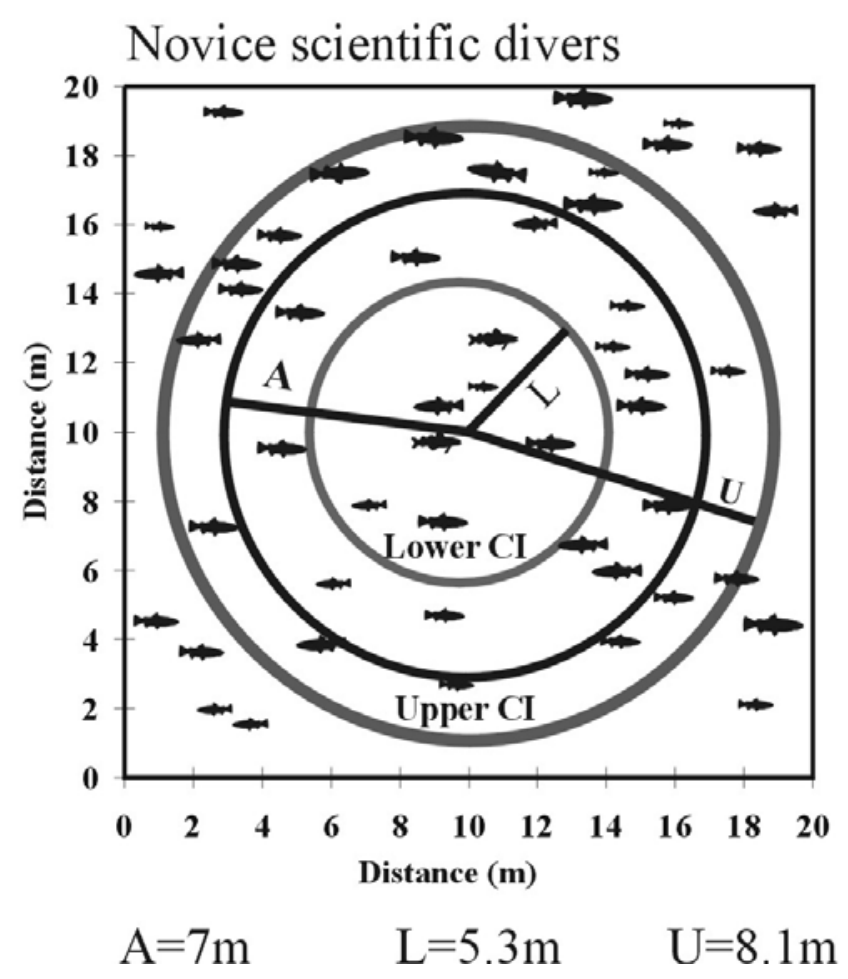


Figure 2(b)

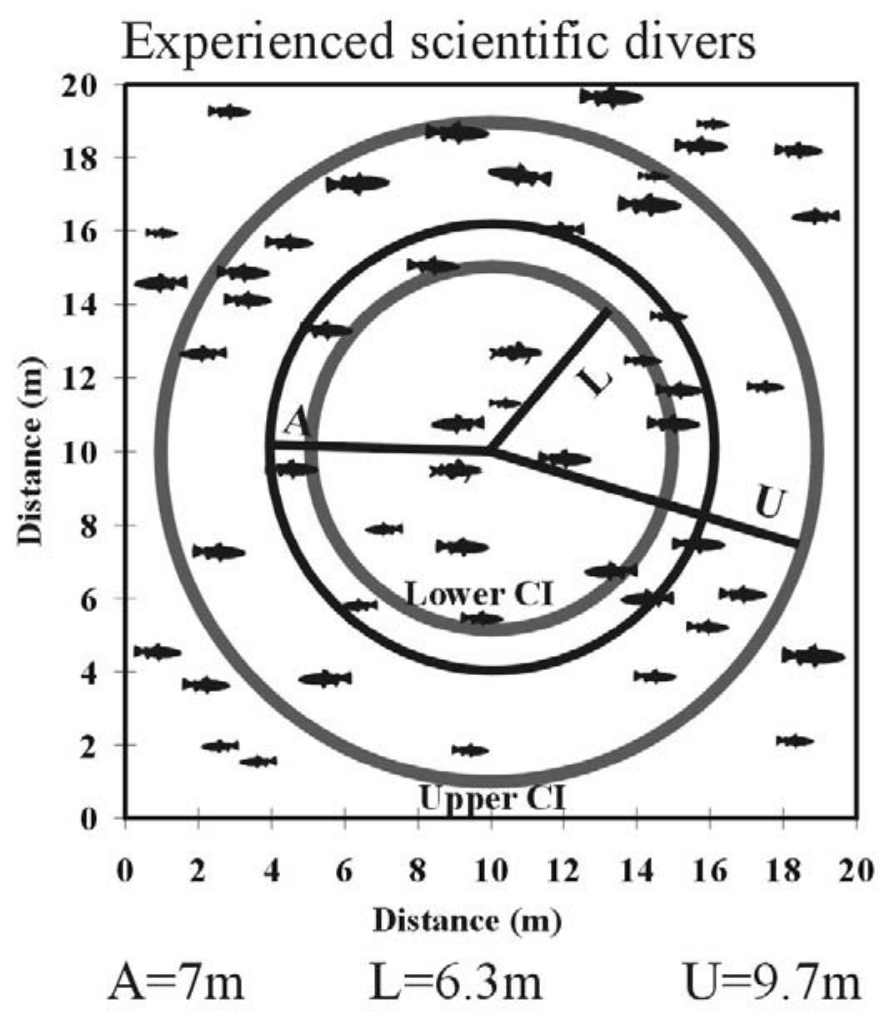


Figure 2(c)

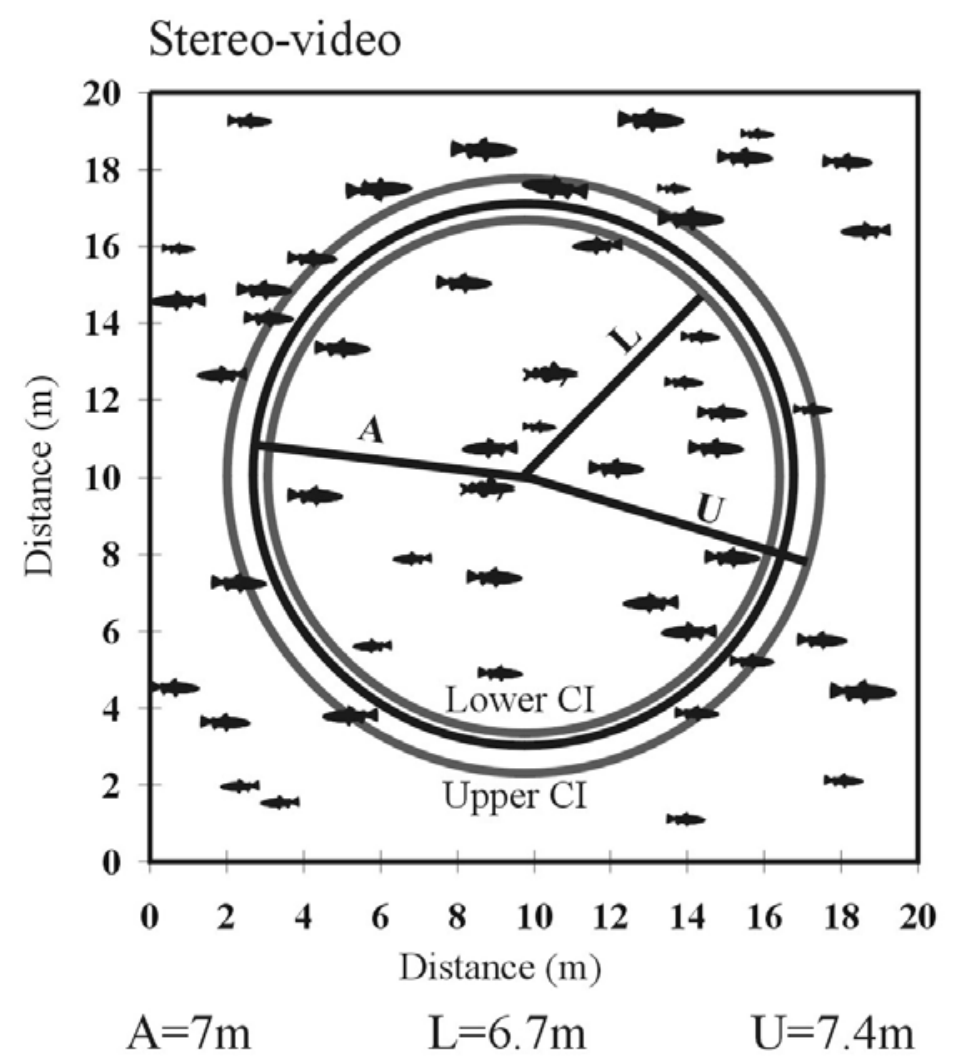


Figure 3a Novice Scientific Divers

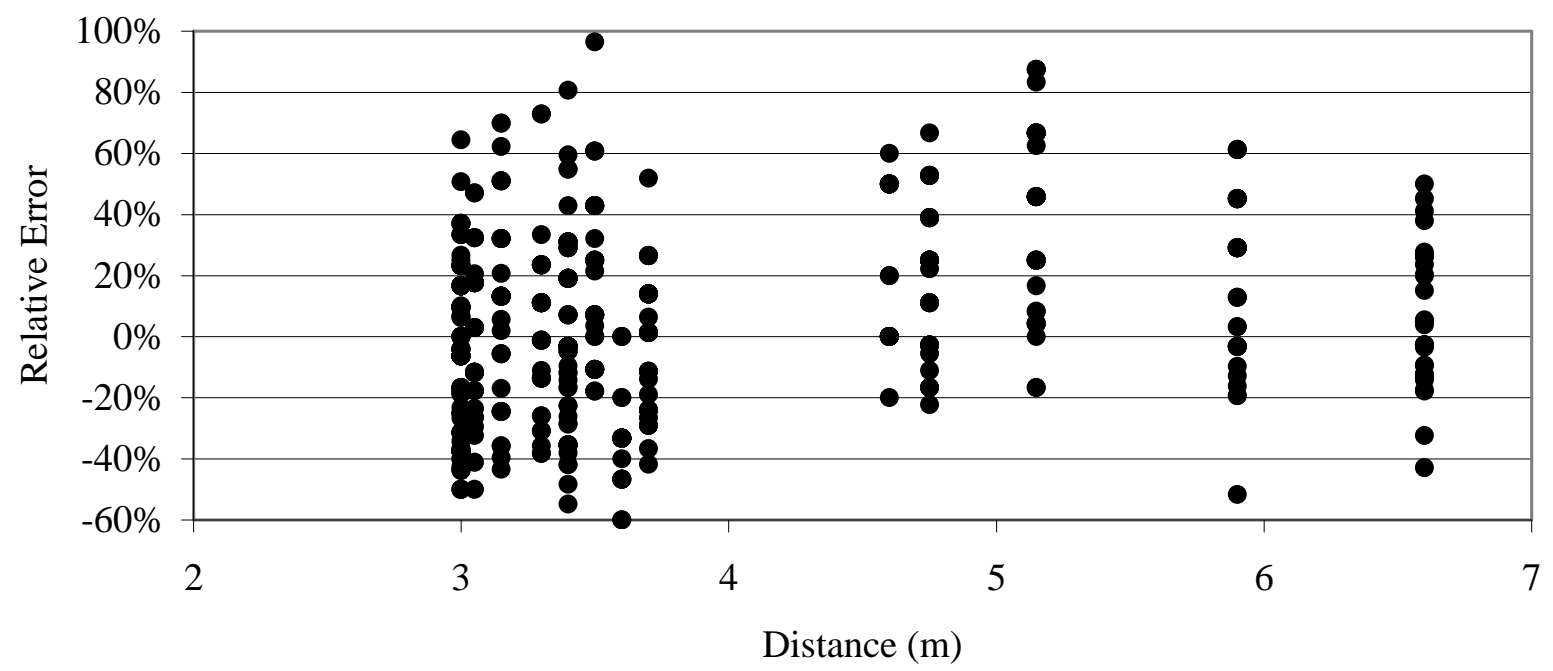

Figure 3b Experienced Scientific Divers

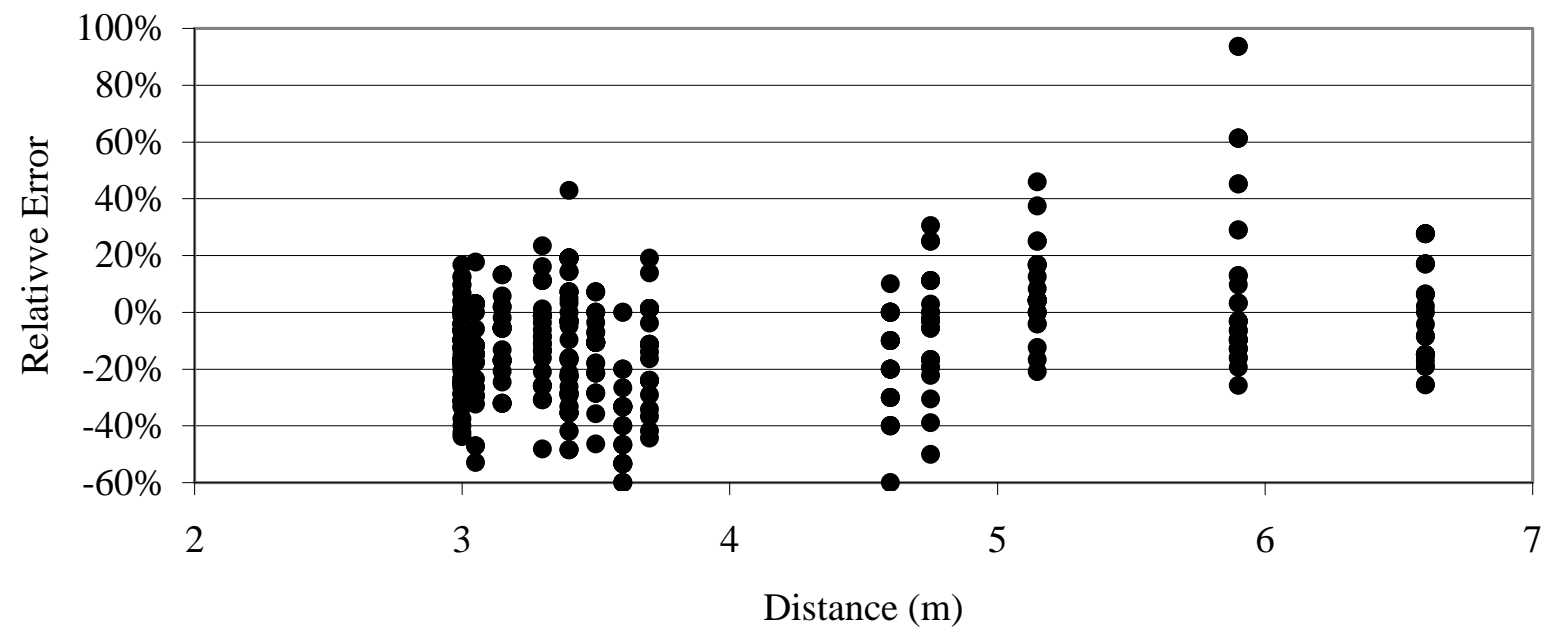


Figure 4a Diver 1

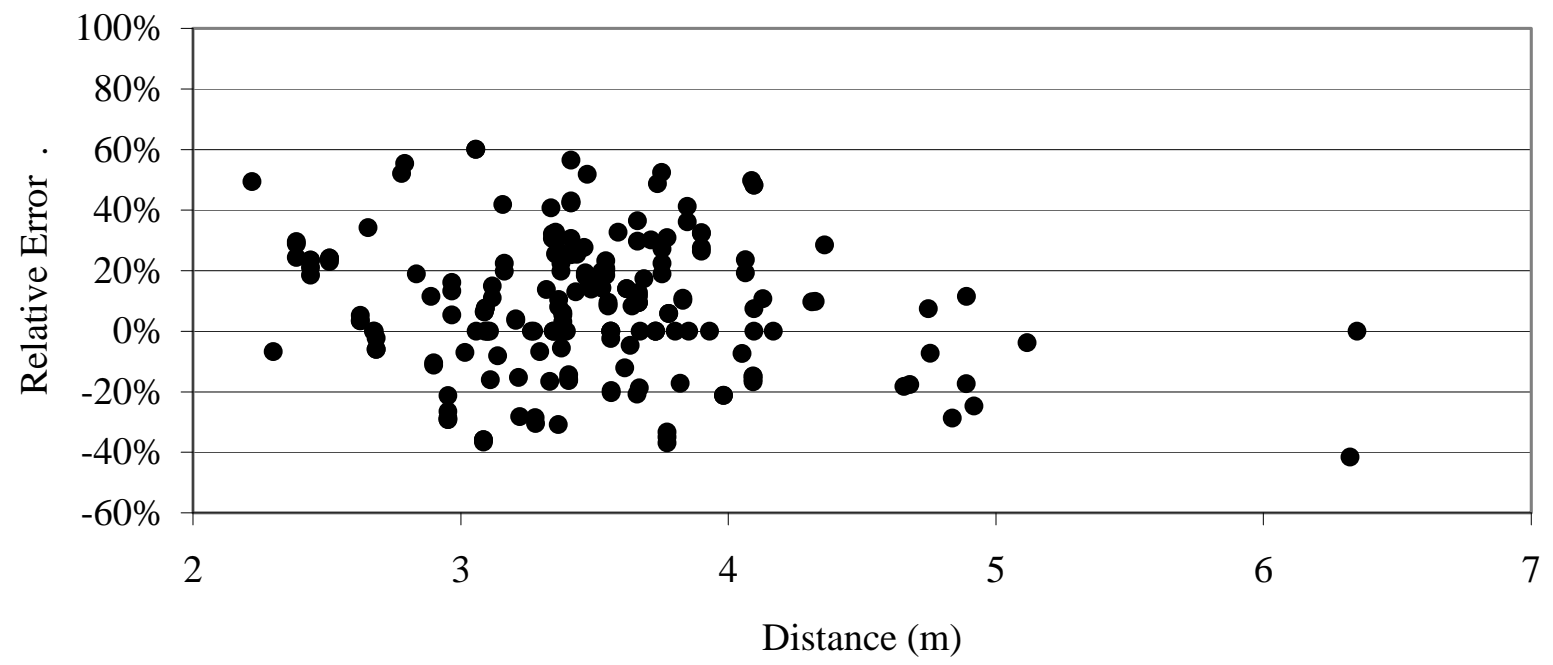

Figure 4b Diver 2

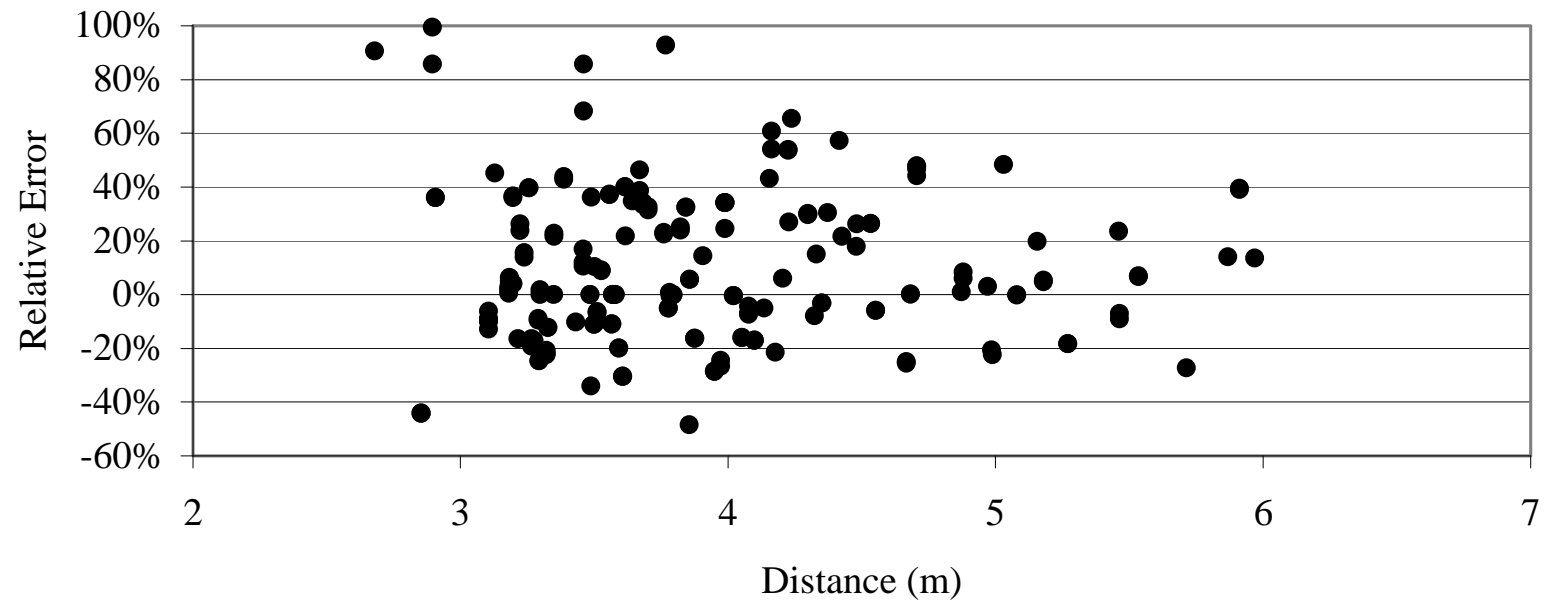

Figure 4c Diver 3 


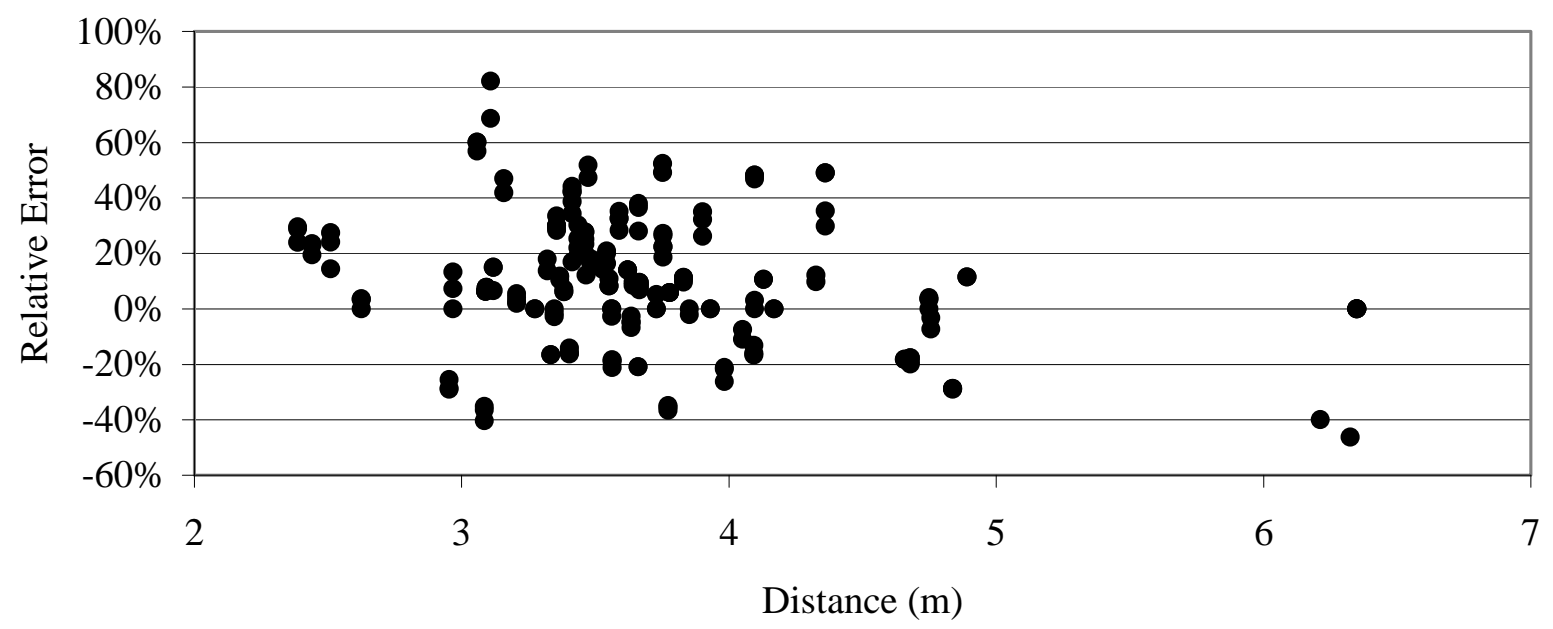


Table 1.

$\begin{array}{ccc}\text { Novice } & \text { Experienced } & \text { Stereo- } \\ \text { Scientific } & \text { Scientific Divers } & \text { Video } \\ \text { Divers } & & \\ & & \end{array}$

\begin{tabular}{rrrrr}
\hline & & & & \\
Relative Error & Mean & $-5.0 \%$ & $-11.7 \%$ & $-0.9 \%$ \\
& SD & $18.6 \%$ & $18.1 \%$ & $2.6 \%$ \\
& Min & $-44 \%$ & $-29 \%$ & $-7 \%$ \\
& Max & $+58 \%$ & $+46 \%$ & $+7 \%$ \\
Coefficient of & & $17.9 \%$ & $21.4 \%$ & $2.1 \%$ \\
Variation & & & &
\end{tabular}

Table 2.

\begin{tabular}{ccccc} 
& & $\begin{array}{c}\text { Novice } \\
\text { Scientific } \\
\text { Divers }\end{array}$ & $\begin{array}{c}\text { Experienced } \\
\text { Scientific Divers }\end{array}$ & $\begin{array}{c}\text { Stereo- } \\
\text { Video }\end{array}$ \\
\hline \multirow{2}{*}{ Distance } & Lower & $76 \%$ & $91 \%$ & $96 \%$ \\
& Upper & $116 \%$ & $139 \%$ & $106 \%$ \\
\hline \multirow{2}{*}{ Area } & Lower & $58 \%$ & $82 \%$ & $93 \%$ \\
& Upper & $134 \%$ & $194 \%$ & $113 \%$
\end{tabular}

Table 3

\begin{tabular}{rcccc} 
& & $\begin{array}{c}\text { Novice } \\
\text { Scientific } \\
\text { Divers }\end{array}$ & $\begin{array}{c}\text { Experienced } \\
\text { Scientific Divers }\end{array}$ & $\begin{array}{c}\text { Stereo- } \\
\text { Video }\end{array}$ \\
\hline Area & Lower & $89.0 \mathrm{~m}^{2}$ & $127.7 \mathrm{~m}^{2}$ & $143.7 \mathrm{~m}^{2}$ \\
& Upper & $207.4 \mathrm{~m}^{2}$ & $286.8 \mathrm{~m}^{2}$ & $173.9 \mathrm{~m}^{2}$ \\
& Actual & $154.1 \mathrm{~m}^{2}$ & $154.1 \mathrm{~m}^{2}$ & $154.1 \mathrm{~m}^{2}$ \\
Abundance & Lower & 31 & & \\
& Upper & 13 & 35 & 20 \\
& Actual & 20 & 20 & 20
\end{tabular}


Captions for figures and tables.

Figure 1. The accuracy of visual estimates of distance by experienced and novice scientific divers and a stereo-video system. The estimates are represented by the crosses while the dotted line represents the real distance. The solid lines above and below the dotted line represent the $95 \%$ confidence intervals.

Figure 2. The effect of error in distance estimates for novice (a), and experienced scientific divers (b) and a stereo video system (c) on the actual area censused for a $7 \mathrm{~m}$ point count. The actual border of the point count is represented by the middle black line (A) while the outer and inner lines represent the upper (U) and lower (L) confidence intervals of the borders. The symbolised fish help to visualise the potential effect that distance error may have on counts of fish abundance.

Figure 3. The distribution of the relative error of length for novice (a) and experienced (b) scientific divers collected under controlled conditions on silhouettes of fish.

Figure 4. The distribution of the relative error of length for three experienced scientific divers $(\mathrm{a}=$ Diver 1, b = Diver 2, c = Diver 3) collected under field conditions with real fish. $\mathrm{N}=200$ for each diver.

Table 1. Summary statistics for visual distance estimates made by novice and experienced scientific divers and an underwater stereo-video system. The coefficient of variation shown is the average over the set of true distances.

Table 2. Confidence limits for the true radial distance and area censused during a point count based on visual distance estimates made by novice and experienced scientific divers and an underwater stereo-video system. All limits are expressed as percentages of the estimate, for a point count with a nominal radial distance of $7 \mathrm{~m}$. 
Table 3. Confidence limits for the actual area censused during a point count and the numbers of fish counted within each interval. All limits are expressed as $\mathrm{m}^{2}$ or numbers of fish for a point count with a nominal radial distance of 7 . 